\title{
Distributed feedback laser amplifiers combining the functions of amplifiers and
} channel filters

\author{
Wang, Z.; Durhuus, T.; Mikkelsen, Benny; Stubkjær, Kristian
}

Published in:

Applied Physics Letters

Link to article, DOI:

$10.1063 / 1.111708$

Publication date:

1994

Document Version

Publisher's PDF, also known as Version of record

Link back to DTU Orbit

Citation (APA):

Wang, Z., Durhuus, T., Mikkelsen, B., \& Stubkjær, K. (1994). Distributed feedback laser amplifiers combining the functions of amplifiers and channel filters. Applied Physics Letters, 64(16), 2065-2067.

https://doi.org/10.1063/1.111708

\section{General rights}

Copyright and moral rights for the publications made accessible in the public portal are retained by the authors and/or other copyright owners and it is a condition of accessing publications that users recognise and abide by the legal requirements associated with these rights.

- Users may download and print one copy of any publication from the public portal for the purpose of private study or research.

- You may not further distribute the material or use it for any profit-making activity or commercial gain

- You may freely distribute the URL identifying the publication in the public portal 


\title{
Distributed feedback laser amplifiers combining the functions of amplifiers and channel filters
}

\author{
Z. Wang, a) T. Durhuus, B. Mikkelsen, and K. E. Stubkjaer \\ Center for Broadband Telecommunications, Electromagnetics Institute, Technical University of Denmark, \\ DK-2800 Lyngby, Denmark
}

(Received 20 August 1993; accepted for publication 28 January 1994)

\begin{abstract}
A dynamic model for distributed feedback amplifiers, including the mode coupled equations and the carrier rate equation, is established. The presented mode coupled equations have taken into account the interaction between fast changing optical signal and the waveguide with corrugations. By showing the possibility of amplifying 100 ps pulses without pulse broadening, we anticipate that a distributed feedback amplifier can be used as a combined amplifier and channel filter in high bit rate transmission systems.
\end{abstract}

Distributed feedback (DFB) amplifiers are very attractive for optical filtering because they can serve both as channel and noise filters and at the same time provide optical amplification. They may be used as filters in switching networks or as receiver amplifiers in multichannel direct detection systems. ${ }^{1}$ Amplifiers incorporating DFB structures have also been suggested for wavelength converters. ${ }^{2}$ For such applications, it is important to understand the dynamic behavior of DFB amplifiers when they are used at high bits rate. It is especially interesting to observe the influence of the very narrow gain spectrum on short optical pulses.

Here we report a dynamic model for DFB amplifiers. It accounts for both the temporal and longiludinal variation of the electric field distribution and the carrier distribution. Using this model, the amplification of narrow optical pulses has been studied. Due to the gain spectrum with a bandwidth in the $\mathrm{GHz}$ range, the behavior of DFB amplifiers in pulse amplification is fundamentally different from that of traveling wave amplifiers, which have been studied extensively. ${ }^{3,4}$ In this letter, we are going to report amplification of $100 \mathrm{ps}$ pulses to ensure that DFB amplifiers can be used as combined channel filters and amplifiers in high bite rate transmission systems.

If ultrafast phenomena, including amplification of very short optical pulses or fast optical switching are considered, then the terms which account for the variation of the electric field with time have to be included in contrary to the static mode coupled equations that are normally derived for DFB structures. ${ }^{5,6}$ Starting from Maxwell's equations and following the same procedure as in Ref. 5, the dynamic coupled equations $\operatorname{are}^{7}$

$$
\begin{gathered}
\frac{\partial A}{\partial z}+\frac{1}{v_{g}} \frac{\partial A}{\partial t}-\frac{1}{2}(1-j \alpha)\left(\Gamma g-\alpha_{i}\right) A \\
=\kappa \exp (2 j \delta z)\left(B+\frac{j \partial B}{\pi \nu \partial t}\right),
\end{gathered}
$$

a)Present address: Lasertron, 37 North Ave., Burlington, MA 01803.

$$
\begin{gathered}
-\frac{\partial B}{\partial z}+\frac{1}{v_{g}} \frac{\partial B}{\partial t}-\frac{1}{2}(1-j \alpha)\left(\Gamma g-\alpha_{i}\right) B \\
=\kappa \exp (-2 j \delta z)\left(A+\frac{j \partial A}{\pi \nu \partial t}\right)
\end{gathered}
$$

where $A(z, t)$ and $B(z, t)$ are the electric field distributions along the cavity for the wave propagating in the positive and negative $z$ directions, respectively. $\delta$ is the detuning of the propagation constant from the Bragg condition, and $\nu_{g}$ is the group velocity of light inside the cavity. $\kappa$ is the mode coupling coefficient, $\alpha$ the linewidth enhancement factor, $\alpha_{i}$ the internal loss and $\nu$ the optical frequency. $g$ is the material gain per unit length and varies linearly with the carrier density, $N$ which is governed by ${ }^{3}$

$$
\begin{aligned}
\frac{\partial N(z, t)}{\partial t}= & \frac{I}{q V}-\frac{a\left[N(z, t)-N_{0}\right]}{h \nu}\left[|A(z, t)|^{2}+|B(z, t)|^{2}\right] \\
& -\frac{N(z, t)}{\tau_{c}},
\end{aligned}
$$

where $I$ is the bias current, $q$ the electron charge, and $V$ the volume of the active region. The carrier lifetime is denoted by $\tau_{c}$ and $a$ is the differential gain. $h$ is Planck's constant, and $N_{0}$ is the carrier density at transparency.

From the right side of Eqs. (1) and (2), we can see that the time variation of the forward and backward traveling electric fields $A$ and $B$ will affect the coupling between the two fields. The modification of the coupling coefficient will result in changes in peak gain level and the detuning of the optical frequency for the gain peak. 'I'his will change the transmission characteristics of DFB amplifiers.

Equations (1)-(3) constitute the theoretical framework for the description of the dynamics of DFB laser amplifiers. In the following, the facets are assumed have zero reflectivity and the influence of spontaneous emission is ignored since it is not important for studies of fast phenomena. ${ }^{4}$ The numerical simulations have been performed by adopting the method of characteristics. ${ }^{8}$ The method of characteristics is difficult to explain in a simple manner, but the basic idea is to transform the differential equations to another coordinates system 
TABLE I. The value of the parameters.

\begin{tabular}{ll}
\hline \multicolumn{1}{c}{ Parameter } & \multicolumn{1}{c}{ Value } \\
\hline Wavelength, $\lambda(\mu \mathrm{m})$ & 1.55 \\
Group refractive index, $n_{g}$ & 3.5 \\
Carrier lifetime, $\tau_{c}(\mathrm{~ns})$ & 2.0 \\
Differential gain coefficient, $a\left(\mathrm{~m}^{2}\right)$ & $2.7 \times 10^{-20}$ \\
Confinement factor, $\Gamma$ & 0.3 \\
Thickness of the active layer, $d_{a}(\mu \mathrm{m})$ & 0.15 \\
Width of the active layers, $w(\mu \mathrm{m})$ & 3.0 \\
Cavity length, $L(\mu \mathrm{m})$ & 500 \\
Electronic charge, $q(C)$ & $1.6 \times 10^{-19}$ \\
Planck's constant, $h(J-s)$ & $6.62 \times 10^{-34}$ \\
Transparency's constant, $N_{0}\left(\mathrm{~cm}^{-3}\right)$ & $1 \times 10^{18}$ \\
Group light velocity, $v_{g}=c / n_{g}\left(\mathrm{~ms}^{-1}\right)$ & $0.86 \times 10^{8}$ \\
Volume of the active layer, $V=d_{a} w L\left(\mu \mathrm{m}^{3}\right)$ & 225 \\
\hline \hline
\end{tabular}

where the partial differential equations are transferred to normal differential equations. Thereby the necessary computer time is significantly reduced. The values of the parameters used in the calculation are listed in Table I.

The steady-state gain characteristics of DFB laser amplifiers can be investigated by using Eqs. (1) and (2) with $\partial / \partial t$ $=0$. An example of the static gain spectrum for a DFB amplifier with $\kappa L=3.0$ is shown in Fig. 1 for a bias of $99 \%$ of the threshold. Since we consider an ordinary DFB structure without a $\lambda / 4$ shift, the maximum gain of $36 \mathrm{~dB}$ is found for a detuning of $121 \mathrm{GHz}$ from the Bragg frequency (only half of the spectrum is shown here). The high bias level results in a very sharp gain spectrum with a $3 \mathrm{~dB}$ bandwidth lower than $1 \mathrm{GHz}$. The above calculation shows that the filtering characteristics of DFB amplifiers is only valid for a weak unmodulated optical signal (optical power is so low that gain saturation does not occur inside the cavity) since the filter is built up by multiresonance of the optical signal. Here we have studied the transmission of a short optical pulse by DFB laser amplifiers, where the interaction between the fast optical signal and the medium with the grating will play an important role.

Different from the case of traveling wave amplifier, there are output from both front and rear facets of a DFB amplifier when signal is injected from front facet. As an example, Fig. 2 shows the transmitted and reflected pulses from the amplifier when a weak pulse is injected. The input pulse is Gauss-

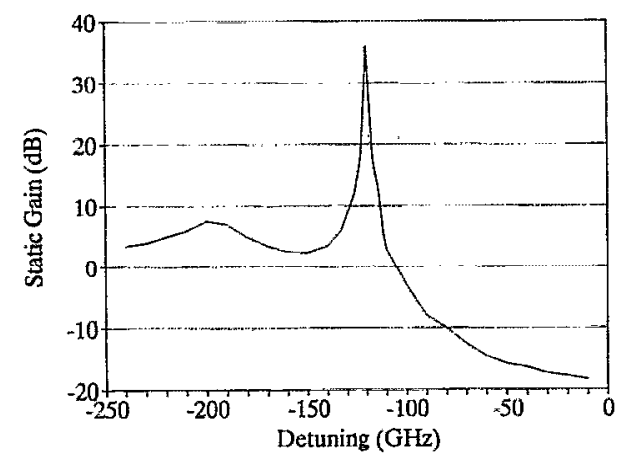

FIG. 1. Steady-state gain spectrum of a DFB amplifier with $\kappa L=3.0$ and $I / I_{\mathrm{th}}=99 \%$.

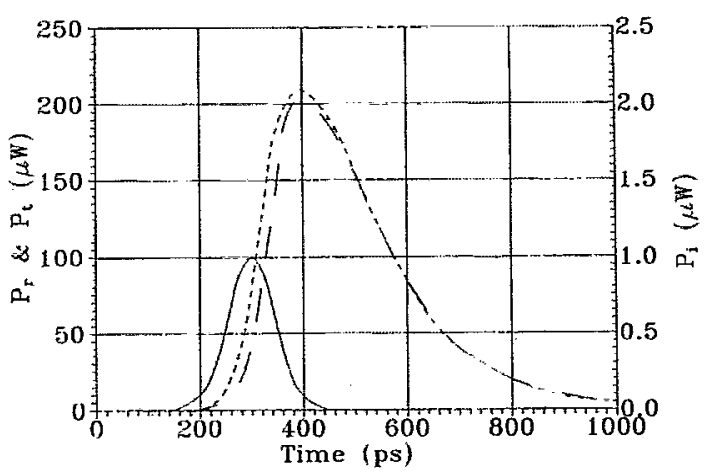

FIG. 2. Power of teflected (short-dashed), transmitted (long-dashed) and input pulses(solid). The input pulse have a FWHM of 100 ps and a peak power of $1 \mu \mathrm{W} . \kappa L=3.0, I / I_{\mathrm{th}}=99 \% . P_{i}, P_{r}$, and $P_{t}$ represent the power of input, reflected, and transmitted pulses, respectively.

ian shaped with a width of 100 ps (full width at halfmaximum) and the bias current is $99 \%$ of threshold. For the weak input case, which has a peak power of $1 \mu \mathrm{W}$ (energy of $0.15 \mathrm{fJ}$ ), the output pulses are broadened to $235 \mathrm{ps}$ due to the filtering characteristics of the amplifier. The gain of the pulse is $23.4 \mathrm{~dB}$, which is $12 \mathrm{~dB}$ lower than that of Fig. 1 .

The pulse broadening is very much dependent on the bias current and the coupling coefficient of the DFB amplifiers. In Fig. 3, we have calculated the pulse amplification characteristics of a DFB laser amplifier with $\kappa L=0.5$ and 3.0. Similar to Fig. 3, the input pulse is 100 ps wide with a peak power of $1 \mu \mathrm{W}$. For $I / I_{\mathrm{th}} \leqslant 0.9$ the pulse broadening is insignificant in accordance with static gain spectra with $3 \mathrm{~dB}$ bandwidths of 19 and $6 \mathrm{GHz}$ for $\kappa L=0.5$ and 3.0, respectively. As $I / I_{\text {th }}$ increase from 0.90 to 0.99 , the pulsewidth is broadened considerably, in agreement with a decrease in the filter bandwidth. The corresponding gain for the case of Fig. 3 is shown in Fig. 4, the gain is increasing with the bias level of the DFB amplifiers relative to its threshold current. The simulation results indicated that DFB amplifiers can be used as a combined filter and preamplifier even at high bitrates if the bias is $10 \%$ below threshold.

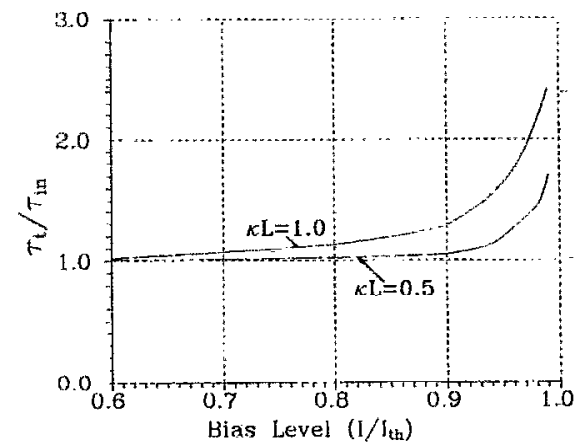

FIG. 3. Pulse broadening as a function of bias level for a $100 \mathrm{ps}$ input pulse, where $\tau_{t}$ and $\tau_{\text {in }}$ are the full width at half-maximum of the transmitted and input pulses. 


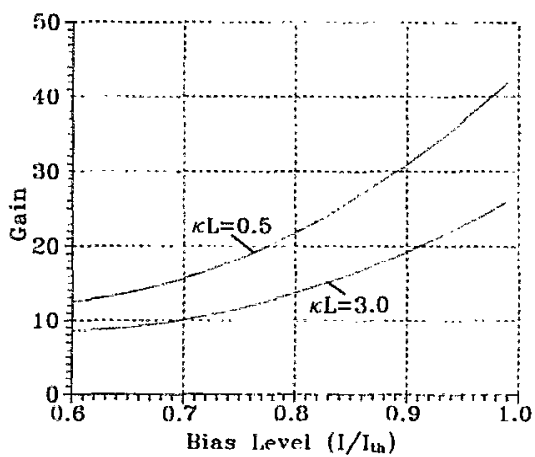

FIG. 4. Gain vs bias level for a 100 ps input pulse.

A dynamic model for DFB amplifiers has been established. The model accounts for the time and position dependence of both the electric field and the carrier density in the DFB amplifier cavity. Simulation results have shown that low power input pulses may be amplified without pulse broadening if the bias is $10 \%$ below threshold. We anticipate that DFB amplifiers can be used as combined preamplifiers and filters in high bit rate transmission system.

${ }^{1}$ E. L. Goldstein, H. Kobrinski, M. P. Vecchi, and R. M. Bulley, Proceedings of the 11th IEEE International Semiconductor Laser Conference, Boston, Aug., 1988, p. 14.

${ }^{2}$ K. Kondo, M. Kuno, S. Yamakoshi, and T. Sakurai, Tech. Dig. Photon. Switching, April 1990, p. 199.

${ }^{3}$ G. P. Agrawal and N. A. Olsson, IEEE J. Quantum Electron. QE-25, 2297 (1989).

${ }^{4}$ P. B. Hansen, J. M. Wiesenfeld, G. Eisenstein, R. S. Tucker, and G. Raybon, IEEE J. Quantum Electron. QE-26, 2611 (1990).

${ }^{5}$ A. Yariv, D. R. Scifres, and R. D. Burnham Quantum Electronics (Wiley, New York, 1987).

${ }^{\circ}$ W. Streifer, D. R. Scifres, and R. D. Burnham, IEEE J. Quantum Electron. QE-13, 134 (1977).

${ }^{7} \mathrm{Z}$. Wang, Ph.D. thesis, Electromagnetics Institute, Technical University of Denmark, 1991.

${ }^{8} \mathrm{R}$. S. Bensen, The Thermodynamics and Dynamics of Internal Combustion Engines (Plenum, New York, 1982). 